\title{
Emergency Corridors - Necessary Solutions in a Modern Road Network
}

\author{
Marcin Dębiński ${ }^{1, *}$, Michał Jukowski ${ }^{1}$, and Janusz Bohatkiewicz ${ }^{1}$ \\ ${ }^{1}$ Lublin University of Technology, Faculty of Civil Engineering and Architecture, Department of \\ Roads and Bridges, 20-618 Lublin, Poland
}

\begin{abstract}
Poland was a place of dynamic road network development in the $20^{\text {th }}$ century. Many expressways and highways were built. Along with the development of the road network, there was a need to introduce new solutions which would be friendly to emergency services. The most important factor influencing the chances of accident victim survival is the time in which first aid will be administered. Reaching the victim is the primary problem for emergency services in case of road incidents. Driver behavior plays an important role, as they have significant effect on emergency service travel times. The emergency corridor is the solution ensuring quick and safe access to expressways and motorways. Examples from Polish roads in 2017 demonstrate that not all drivers are able to behave properly when emergency services move trying to access the accident site (cases of blocking, driving the wrong way through the corridor, etc.). It cannot be clearly assumed that drivers have bad intentions. According to the authors, the problem lies in education, access to information, and lack of regulatory policies. In Austria, Germany and Hungary, a great deal of resources has been devoted to information campaigns on safe behavior in the event of road accidents, and a number of legal provisions have developed allowing the police to ensure that these rules are respected.
\end{abstract}

\section{Introduction}

Characteristic multi-lane sections in case of traffic congestion caused by traffic accidents are difficult to pass for emergency service vehicles. In case of administering first aid during traffic incidents, time is crucial. The golden hour is the time in which the victim should be hospitalized, starting as early as from the moment the event occurred. In case of cardiac arrest, the time to begin cardiopulmonary resuscitation is much shorter and amounts to 4 minutes [1]. After this time, the chances of victim survival fall drastically to zero.

Emergency vehicle drivers encounter many problems with access to accident location. The main problem and threat is the behavior of other drivers, and their lack of knowledge concerning the principles of creating rescue corridors. Lack of proper education and legal regulations deepens this problem.

\footnotetext{
*Corresponding author: m.debinski@pollub.pl
} 


\section{Study Methodology}

As a part of the study, an analysis of exemplary geometric solutions (road cross-sections) was performed with regard to the possibility of creating a rescue corridor. A survey among drivers was carried out in order to verify the knowledge of safe movement rules during the emergency services crossing. In case of geometric parameter analysis of exemplary solutions on expressways and motorways, the vehicle width and the possibility of safely sharing the largest possible width for the passage of emergency vehicles were taken into account.

The study analyzed the trafficability at the specified two vehicle speeds, the distance needed by heavy vehicles to get to the edge of the roadway while creating the directional corridor was specified. Surveys were conducted in order to verify the knowledge of Polish drivers with regard to their behavior towards emergency services. A survey consisting of 23 questions was developed, with positions divided into four groups: questions related to the characteristics of the respondent, questions verifying the knowledge about rules of safe behavior in case of emergency service movement, questions concerning the opinion about the effectiveness of emergency service light and sound signals, and questions concerning the opinion about the emergency corridors. Additionally, surveys were carried out among emergency vehicle drivers and emergency service workers. 24 questions were prepared for them, also divided into four groups: questions characterizing the respondent, questions verifying whether the respondent participated in an accident or collision during a rescue operation, questions concerning the opinion about the effectiveness of light and sound signals, and questions concerning the opinion about emergency corridors. This article presents the selected (most important) results of the survey.

The survey was carried out on a sample of 412 drivers, with 171 women and 241 men. The respondents were in different age groups, the most numerous two age groups are from 18 to 24 years $(46 \%)$ and 25 to 39 years $(47 \%)$. The participants came from 16 voivodeships. The largest group of people participating in the study came from the Lublin Voivodeship The study took into account the distance that the respondents cover as drivers each year. Most people cover a distance of $15,000 \mathrm{~km}$ per year. In case of larger distances, these concern $28 \%$ of respondents.

\section{Test results}

The results presented below define the preparation of road infrastructure in case of rescue actions during road accidents. Based on the surveys, the level of drive knowledge and awareness concerning rescue corridors was determined. The analysis was carried out on three levels. The first level includes the possibility of using a rescue corridor due to the geometric parameters of the road cross-section. The second level includes the drivers' awareness and their knowledge. The third level comprises legal regulations in Poland and examples of solutions from other countries.

\subsection{Geometric parameters of roads}

The road geometry analysis was performed for two exemplary cross-sections. The first analyzed cross-section is the cross-section of the P1-type slip road on the expressway. The second section includes an expressway with an emergency lane. The example of the Volvo FMX technical emergency vehicle (hereinafter also referred to as the reference vehicle) with the following dimensions was used for the analysis:

- length: $8.88 \mathrm{~m}$

- width: $2.54 \mathrm{~m}$ 
- height: $3.50 \mathrm{~m}$

The P1-type slip road was chosen for analysis. It is one of the most common slip roads on interchanges. According to [2], the P1 slip road should have minimum width of $6.00 \mathrm{~m}$ and shoulders with a width of $1.00 \mathrm{~m}$. Fig. 1 shows a truck positioned at the edge of the road without using the shoulder. This is due to truck drivers' fear of driving on the shoulder or hitting the barriers. As can be seen, there may be an approx. $40 \mathrm{~cm}$ wide free space left on both sides of the technical emergency vehicle. Depending on the vehicle's position, the distance between the vehicles can wide enough to ensure safety - the safe passage of the privileged vehicle will be determined by its speed.

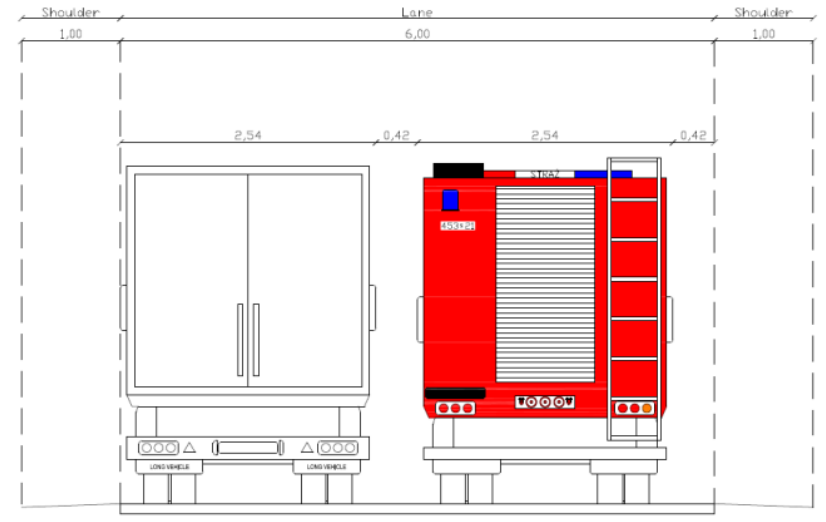

Fig. 1. Privileged vehicle in the cross-section of the P1 slip road.

In accordance with the Regulation on technical conditions for roads [2], the required lane width for the dual carriageway expressway is $3.5 \mathrm{~m}$. For this road, an emergency lane with a width of $2.5 \mathrm{~m}$ should also be used. The entire roadway width in this section is 9.5 $\mathrm{m}$. The S12 Lublin-Piaski road forms an examples of such a solution. This section has been analyzed for the possibility of using a rescue corridor.

In the cross-section, the outlines of trucks were placed at the extreme edges of the road, as in case of recommendations for the formation of a rescue corridor. A reference vehicle was added to the space formed by doing so. Between the extreme elements of vehicles, the measured distance is over $80 \mathrm{~cm}$. This distance provides the possibility to maneuver freely and ensures safety distance. It should be noted that this section provides the possibility of using a rescue corridor. The results of the analysis are presented in Fig.2.

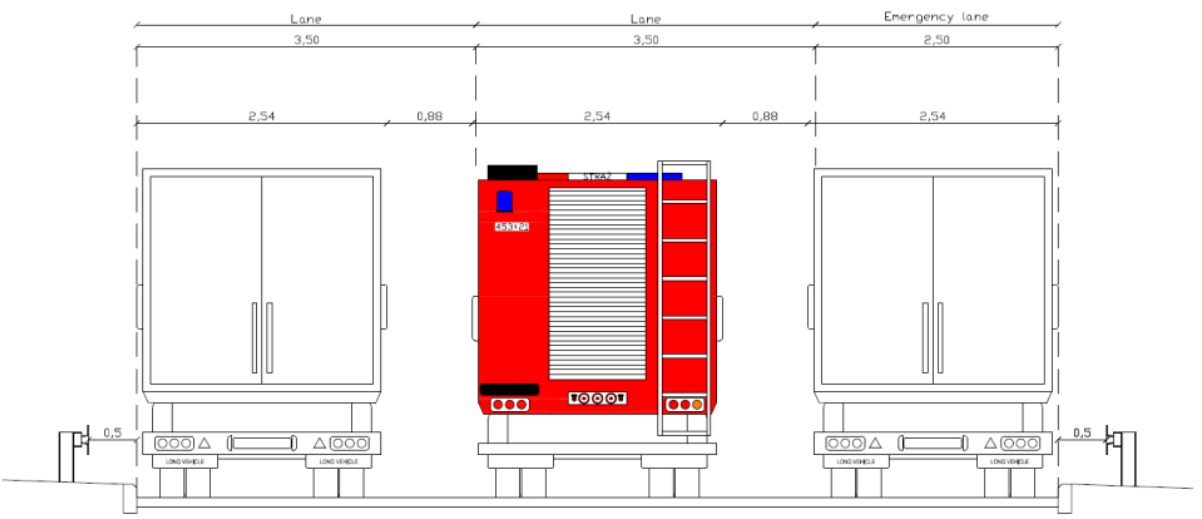

Fig. 2. Privileged vehicle in the cross-section of the $\mathrm{S}$ class road in urban area. 
Road infrastructure solutions designed and built using technical conditions for roads [2] meet the needs arising from rescue corridor use. With a fast, efficient and conscious reaction of drivers, it is possible to easily and quickly share the necessary space for the emergency services' movement within the rescue corridor.

\subsection{Drivers' behavior towards emergency services}

Surveys were conducted in order to verify the awareness and potential behavior of drivers towards emergency services and emergency corridors. The surveys consisted of 23 questions concerning the situation in case of drivers' behavior towards emergency services. The questions regarding the emergency corridors were subject to careful analysis. The first question concerned safe behavior on the road.

According to the results of the survey among 412 respondents, the question "Do you think you know how to behave during the emergency services movement?", met with positive response from $93 \%$ respondents. $3 \%$ of people (drivers) stated they did not know how to behave during emergency services movement.

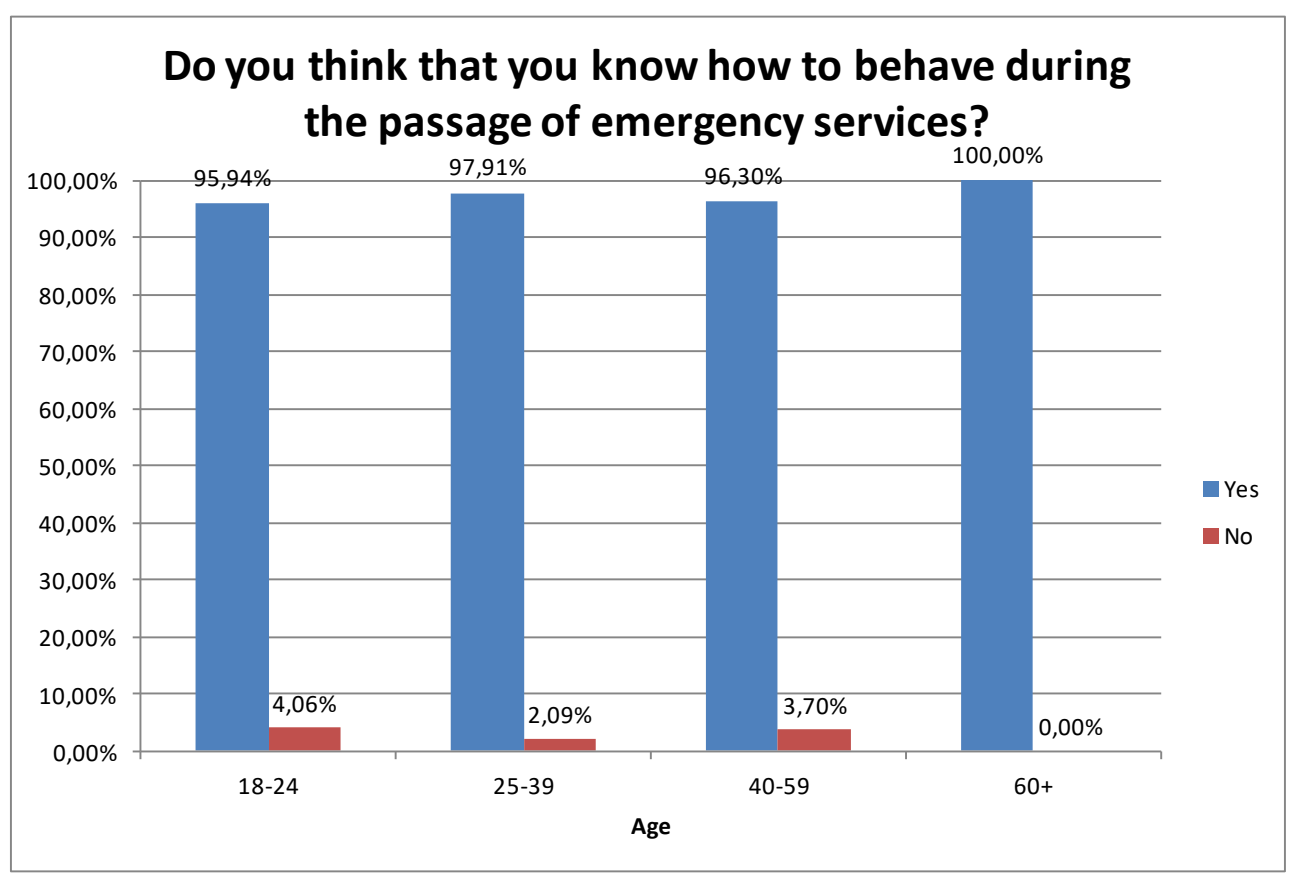

Fig. 3. The results of the survey on knowledge of the rules during an emergency action on a road depending on the age of the respondents.

The respondents were also asked if they knew what an emergency corridor was. $16 \%$ of respondents replied with negative response. These results do not match the previous question, where only $3 \%$ of people stated that they do not know how to behave towards privileged vehicles. 


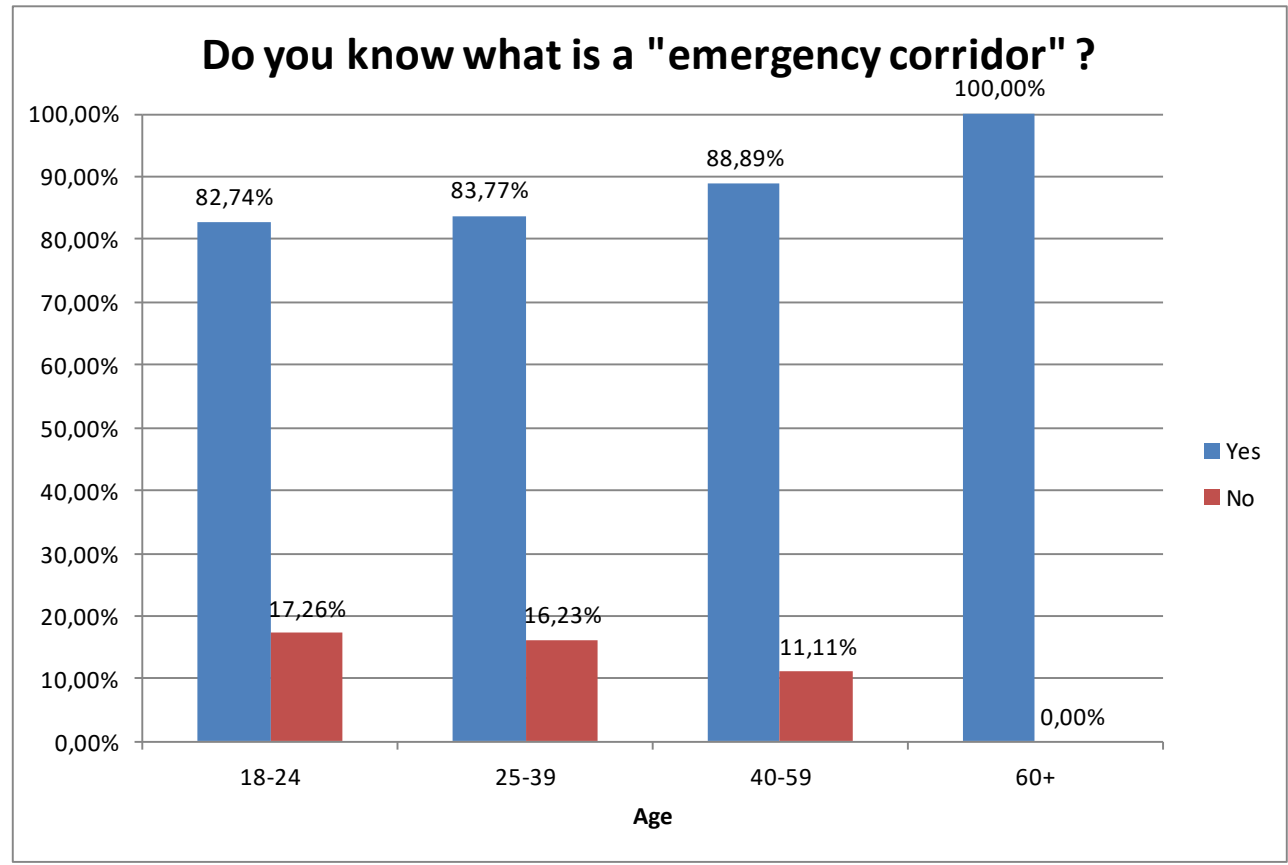

Fig. 4. The results of the survey on knowledge of an emergency corridor depending on the age of the respondents.

The next question was a control question related both to the behavior of drivers emergency services movement, and the knowledge about the rescue corridor formation. Answers indicate that $31 \%$ of respondents do not know the basic rules of behavior towards privileged vehicles, as they selected the answer that an emergency corridor is formed on the emergency lane. Only $69 \%$ of the respondents provided the correct answer. These results indicate that drivers are not aware of the way the rescue corridor is formed and how it operates. Among those who answered the question "Do you think you know how to behave during the emergency services movement" affirmatively, over $30 \%$ of the respondents provided wrong answer to the control question.

In case of respondents who provided affirmative response to the question: "Do you know what an emergency corridor is?" $25.5 \%$ of them gave incorrect answer to the control question. These differences may result from the lack of awareness of correct behavior towards the emergency services. The results of the survey may indicate the lack of up-todate knowledge of drivers about the road behavior as well as too little informative actions in the media on proper behavior and formation of the emergency corridor during a passage of the emergency services.

\subsection{Polish legal regulations and foreign examples}

Regulations regarding emergency corridors are present in Austria, Switzerland, Germany, the Czech Republic and Hungary. Austria has the strictest rules which have been in force since 2012 [5]. The penalty for failure to establish an emergency corridor is over EUR 2,000. In 2017, Germany introduced stricter rules by raising penalties for non-compliance with the emergency corridor, ranging between EUR 240 and EUR 320. In Germany, in addition to the financial penalty, there is also a penalty of driver license suspension for 1 month. In case of victim's death, the person who contributed to blocking the passage of emergency services may be subject to restriction of personal liberty for one year. In case of 
Poland, the Ministry of Infrastructure and the National Road Safety Council intend to introduce legal regulations to the Road Traffic Law, beginning from 2018. The definition of an emergency corridor will be introduced to the content of the Law. The introduction of these changes will enable to introduce penalties for non-compliance with the rules of emergency corridors. Driving instructors will be required to convey the ideas and rules for forming an emergency corridor correctly. The driving test will permanently address the issues related to safe behavior on roads towards the emergency services. In addition, an obligation to possess a first-aid kit in the car is planned to be introduced. All these regulations should also be promoted by the media in order to improve road safety.[6]

\section{Conclusions}

The performed analyses indicated that new roads of higher technical classes designed in accordance with the technical conditions for road design are adapted to emergency corridor formation. Similarly, slip roads on interchanges should not be a hindrance to emergency services, provided fast driver response is present. Surveys have demonstrated that one-third of drivers do not know how to form a rescue corridor, at the same time claiming (in case of almost all drivers) that they know the rules of behavior during emergency services' movement. Despite the increasing media coverage of emergency corridors and information campaigns, according to the paper's authors, awareness and knowledge about safe behavior during traffic incidents are still insufficient. Providing help for accident victims should be regulated by provisions of the law which should provide privileges to emergency services, as well as penalties for drivers who break the rules (similar to the countries that have these provisions in force). It is necessary to introduce regulations concerning emergency corridor formation as soon as possible, and it is necessary to educate drivers with regard to this topic. The media present one of the most important roles in this area.

\section{References}

1. R.W. Kostera, M.A. Baubinb, L.L. Bossaertc, A. Caballerod, P. Cassane, M. Castrénf, C. Granjag, A.J. Handleyh, K.G. Monsieursi, G.D. Perkinsj, V.R. Ayk, C. Sandronil, Podstawowe zabiegi resuscytacyjne u osób dorosłych oraz zastosowanie automatycznych defibrylatorów zewnętrznych (AED), in: Wytyczne Resuscytacji, (Polska Rada Resuscytacji, Cracow, Poland, 2010)

2. Regulation of the Minister of Transport and Maritime Economy of 2 March 1999 on technical conditions for public roads and their location, OJ 1999 No. 43 Pos. 430 (Poland, 1999)

3. Act of 20 June 1997 - Road Traffic Act, OJ 1997 No. 98 Pos. 602 (Poland, 1997)

4. www.dekra.de, (2018)

5. www.asfinag.at, (2018)

6. www.trans.info, (2018)

7. M. Dębiński, M. Jukowski, J. Bohatkiewicz, Drogowe korytarze ratunkowe, in: VI Konf. BRD Pol. Kongresu Drog. Ratow. Na Drog., (Kazimierz Dolny, Poland, 2015)

8. Bulletin of Polish State Fire Service, (2018) 